\title{
Public toilets: an exploratory study on the demands, needs, and expectations in Turkey
}

\author{
Yasemin Afacan \\ Department of Interior Architecture and Environmental Design, Faculty of Art, Design and \\ Architecture, Bilkent University, TR-06800 Bilkent, Ankara, Turkey; \\ e-mail: yasemine@bilkent.edu.tr
}

Meltem O Gurel

Department of Architecture, Faculty of Art, Design and Architecture, Bilkent University, TR-06800 Bilkent, Ankara, Turkey; e-mail: mogurel@bilkent.edu.tr

Received 12 February 2013; in revised form 22 December 2013; published online 20 June 2014

\begin{abstract}
Provision of public toilets is not only a matter of land use, but also an essential design and planning concern. This study examines the following questions through an explanatory study. (i) What problems do public toilets pose? (ii) What toilet facilities do people require most and/or most emphasize would affect the way they use land and participate in social life? (iii) How do demands, needs, and expectations around public toilets change depending on gender, age, and ability? We conduct a survey of 300 people in fourteen public restrooms in the city centre of Ankara, Turkey. According to factor analysis results, public toilets should be seen as potential urban spaces and initial opportunities for sustainable urban developments and liveable cities.
\end{abstract}

Keywords: public toilets, discrimination, inclusive design, gender, disability, equal participation

\section{Introduction}

Public toilets should be seen as a core component of environmental design, adding to a city's quality and viability (Greed, 2004). Provision of public toilets is not only a matter of land use, but also an essential design and planning concern to make cities more accessible, inclusive, and convenient for all members of society. Public toilet provision often overlooks the needs (and even the existence) of women, children, disabled people, and the elderly. Ensuring public toilet provision is available to everyone can be considered essential to removing a serious barrier to wider participation in public life (Knight and Bichard, 2011). Moreover, evidence indicates that inclusively and well-designed neighbourhood outdoor spaces positively contribute to people's health and quality of life (Aspinall et al, 2010). Therefore, in this study, it is argued that designing public toilets affects how people use land and participate in social life. Many people, such as the elderly and disabled, travel seldom, rarely go outside and avoid long journeys because of the lack of and/or inaccessible design of public toilets (Greed, 1996).

Thus, this explanatory study examines the following three questions. (i) What problems do public toilets pose (ie, what actually exists)? (ii) What toilet facilities do people require most and/or most emphasize would affect the way they use land and participate in social life? (iii) How do demands, needs, and expectations around public toilets change depending on gender, age, and ability? We conclude the paper by proposing guidelines for designers, architects, planners, and policy makers about how the 21 st-century public toilet can allow equality of access, use, and opportunity, regardless of gender, ability, or age. This study contributes to the literature by exploring the provision of public toilets theoretically and investigates user needs experimentally in the Turkish context, as well as by suggesting 
new means through which towns and cities can promote social inclusivity, environmental responsiveness, sustainability, and inclusive urban design.

\section{Literature on public restrooms}

The first scholarly research on restrooms was done by Kira (1966, with the revised edition in 1976) and Wright (1967) who explored social, physical, and cultural issues. In recent years more research on public toilets has been conducted regarding their provision, governance, and implementation policies in governmental, professional, organizational, and cultural contexts (Bichard et al, 2004; Gershenson and Penner, 2009; Greed, 1996; 2003; 2004; 2005; 2009; Gurel, 2008; Hanson et al, 2007; Knight and Bichard, 2011; Molotch and Noren, 2010; Penner, 2005; 2009). According to Kitchin and Law (2001), public toilet design is still at the heart of contemporary struggles over space and "provides a useful illustration of a larger point: how landscapes are constructed through particular power geometries and shaped by notions of citizenships and social justice" (page 287). Greed (2003) emphasizes the necessarily inclusive character of public toilets: "the provision of public toilets should not be seen as an unpleasant low status function, typically in with local authority cemeteries, allotments and waste disposal departments and carried out, albeit with good intentions, by the public works and plumbing fraternity alone" (page 4).

The literature shows that unequal and inadequate toilet provision makes it difficult to achieve sustainable, healthy, and inclusive cities (Bichard et al, 2004). According to the World Health Organization, public toilet provision is defined as a major factor in AgeFriendly Cities (Help the Aged, 2007; Knight and Bichard, 2011). However, toilet provision has remained inadequate in most communities, and also in developing countries such as Ghana, China, and India which lack even rudimentary toilet access (Gershenson and Penner, 2009; Molotch and Noren, 2010). Greed (1996) investigates the provision of public toilets in Britain and suggests that a radical reconceptualization is needed to solve existing toilet problems. Anthony and Dufresne (2007) examine how public restrooms pose health and safety problems specifically for women, children, the elderly, and the disabled. Although there has been a considerable focus on providing accessible public toilets in Europe and the US under disability legislation and human rights acts, not everyone's needs are met (Knight and Bichard, 2011). Toilet limitations significantly restrict people's mobility in cities and their ability to take part in public life (Knight and Bichard, 2011). "The restroom thus becomes a tool for figuring out just how a society functions - what its values are, how it separates from one another, and the kinds of trade-offs that come to be made" (Molotch and Noren, 2010, page 8 ).

Studies and critical analyses around public toilet provision show that access and equality of public toilets is not just a spatial configuration and design issue, but also a political and social issue (Greed, 2009). For this reason, questioning the architectural design and urban planning issues of public toilets should be done through interdisciplinary discussions about and observations of gender, age, and ability. According to Penner (2005), traditional forms of research do not suffice; explorations of this matter must also include a sociocultural perspective. The study by Hanson et al (2007) undertook a comprehensive three-year research project (2003-06) to determine the toilet needs of 548 people in London, Manchester, and Sheffield, England. Significantly, their study addresses the physical, social and political dimensions of public toilet provision. Concerned about access problems, design deficiencies, and sustainability issues, the authors held focus groups and conducted user interviews. Their results are important in terms of providing guidelines on public toilet provision from a more user-oriented perspective, as studies of public conveniences from the user perspective are still comparatively rare. Other resources are helpful when considering the design, location, and management of public toilets (eg, Approved Document M-Access to and Use of 
Buildings, 2004; British Standard BS8300, 2010; Goldsmith, 1997; Lacey, 2004). However, such building codes only set out the type, height, and design of appliances, fixtures, and stalls, and say nothing about how the social patterns relate to and affect these standards. That aspect of public toilets provision should also be explored (Kitchin and Law, 2001; Molotch and Noren, 2010). To fill the above described gap in the literature, in the current study we look at ways of understanding the complex interplay between the social and physical from the public toilet user's perspective and contribute to existing literature by examining public toilet provision in an understudied region (Turkey).

\section{The legislation in Turkey}

In this geography, public squat (hole-in-the-floor) toilets existed beside mosques or as a part of a complex of buildings surrounding mosques (külliye). As such, they can be seen in the Early Ottoman period, for example, in the building complex surrounding Murad Hüdavendigar Mosque in Bursa. Besides "a small domed building containing public toilets" (Kuran, 1968, page 207), the structures around this monumental mosque included an imaret, a primary school, a mausoleum (türbe) and a bath. Worshippers and visitors alike could use the toilets. See figure 1 for an example of a squat toilet from the Ottoman period. According to Atasoy (2000, page 102), Ottomans also used toilet and bath tents, "long before the toilet culture became a customary part of European courts." Toilet and ablution tents were available to ordinary subjects, as well (Atasoy, 2000). Public toilet governance in the whole Ottoman period was conducted by charitable institutions, thus toilet provision and implementation was a social issue (Gulluce, 2004). With the establishment of the Turkish Republic in 1923, the toilet situation began to change due to the creation (albeit somewhat disorganized) of metropolitan and district municipalities and became a financial issue (Aker and Tasdemir, 2010). They became the responsibility of the finance department.

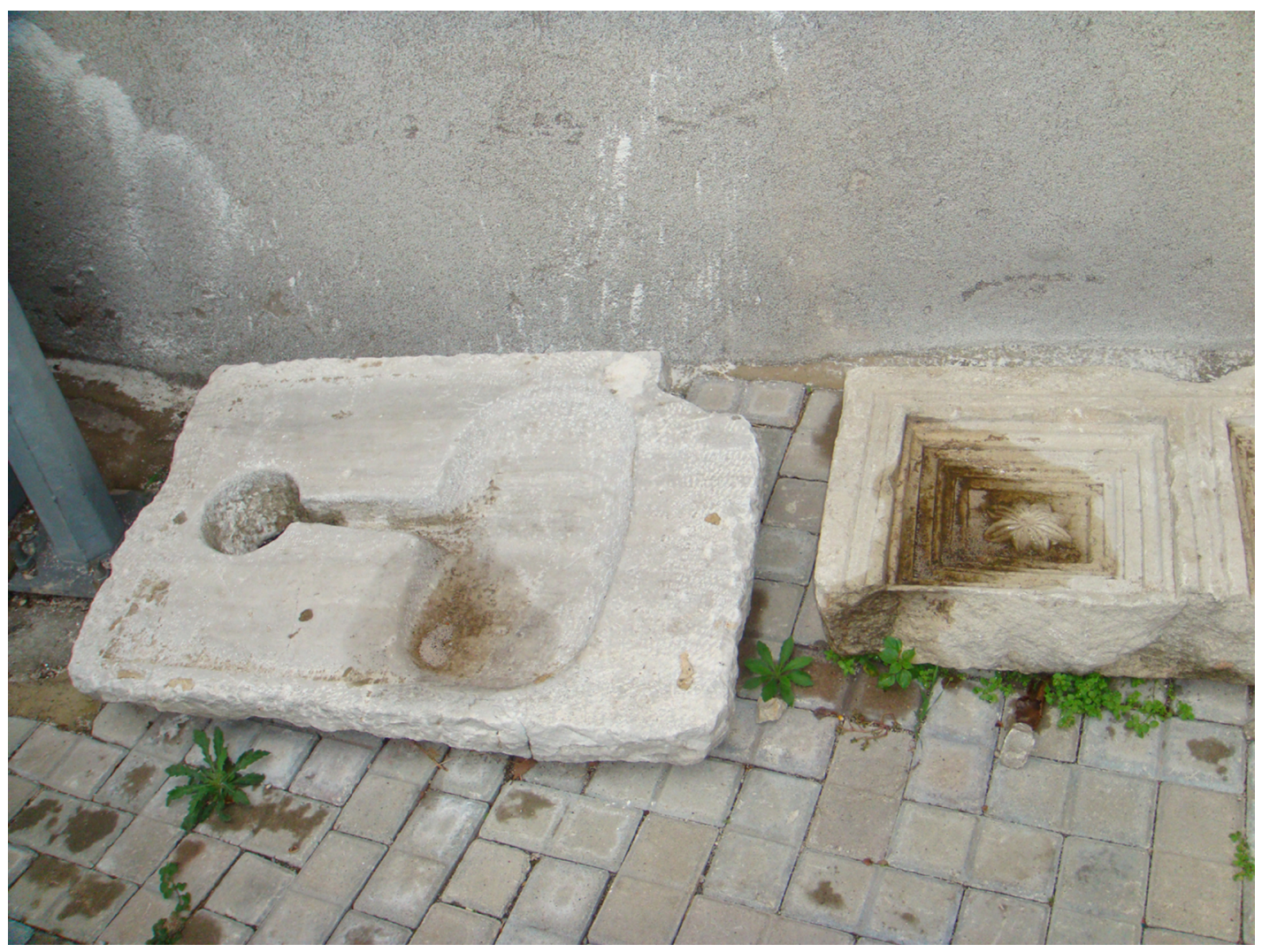

Figure 1. [In colour online.] An example of a squat toilet from the Ottoman period. 
Starting in the 1950s, urban density increased as a result of greater migration from rural areas to cities, and city centres became incapable of undertaking the construction, and the continual maintenance and operation of public toilets (Aker and Tasdemir, 2010). This rapid urbanization necessitated a new legislation and governance structure, which, although now in effect on paper, has not been fully implemented because of inconsistencies and unclear relationships with other legislation (Unsal, 2009). Although there are still toilets beside mosques, detached public toilets remain sex-, ability-, age-, and size-segregated spaces that usually require a fee to use.

The reasons for this situation are as follows: (1) there is no requirement for local authorities and municipalities to provide a fully accessible public toilet; (2) there is no user-participation process with a focus on the toilet needs of diverse people; and (3) public toilet provision is costly to maintain, both financially and environmentally (Aker and Tasdemir, 2010; Ersoy, 1989; 1999; Gulluce, 2004). Moreover, toilet governance in Turkey is fragmented. Not all public toilets are run by local authorities; some are managed by private bodies, among which there is a lack of knowledge, awareness, and sensitivity regarding diverse gender and user needs with reference to land-use patterns and design factors. There is little control by municipalities over how and where individual public toilets are provided, maintained, and operated, therefore, their distribution and location occur arbitrarily, without considering master planning principles, 'healthy urban planning' issues (Barton and Tsorou, 2000), or people's expectations. As a result, society is suffering from deficiencies in its quality of life (Unsal, 2009).

Another issue in need of consideration is the style of toilet fixtures to be used in public restrooms. The squat toilet was the norm in this part of the world until the early 20th century. The throne-style water closet has gained in popularity since the 1950s. As Gurel (2008) argued, simultaneous perception of a water closet as a means of modernity and as a tool of modernization has been an important factor in spreading its use. Moreover, the use of the Western-style water closet, as it is called in Turkey, has suggested the polarity between what is considered modern and traditional (Gurel, 2008). Although throne-style fixtures are widely used in Turkey, many prefer traditional squat-style fixtures and what is considered traditional bodily practices for a variety of reasons ranging from hygienic concerns to conservatism. Needless to say, in a country like Turkey, where religion and secularism is a contested issue, throne-style or squat toilets have greater implications than use alone: the symbolic value in their presence is contentious. Therefore, any legislative decision on restructuring public toilets in Turkey or elsewhere needs to take into consideration the current uses as well as users' perspectives.

\section{Interactions among gender, age, and ability regarding public toilet provision and use}

Starting from the 1990s, access, provision, and use of public toilets for all has become an important part of political and design agendas. However, public toilets in many countries (Australia, New Zealand, the UK, US, Turkey) still reflect discrimination in terms of gender, ability, and age (Anthony and Dufresne, 2007). Goldsmith (1997) discusses the paradigm of designing public toilets in the UK and explains the issue using two concepts, microprovision and macroprovision. Microprovision means special provision for the disabled and macroprovision means provision that accommodates disabled people. Regardless of whether toilets are macroprovision or microprovision, the key question is how they should be designed for different ages, abilities, and genders. "What is good for everyone is good for the disabled" (Goldsmith, 1997, page 97). Serlin (2010) investigated the discourse about equality in public restrooms in the US and highlighted that while public toilets became common throughout the nineteenth and twentieth centuries, they lacked accessibility and usability for disabled people. 
Due to inappropriate and nonexistent facilities, the disabled were excluded from the public sphere (Serlin, 2010). Again, this situation highlights the need for designers to think about this privileged-access issue and how to make public toilets accessible to, and usable for, all. Because "architects, planners and builders until very recently have [had] no obligation to provide accessible toilets in public spaces and buildings, consequently few were installed" (Kitchin and Law, 2001, page 290). In Turkey, legislation regarding the provision of toilet facilities for the disabled in public spaces was accepted in October 2004 (http:// www.icisleri. gov.tr/default.icisleri_2.aspx?id=2943.asp). However, as is evident from the research conducted for this study, the conditions do not match the legislation.

Gender difference in restrooms has also been investigated in terms of behaviour, design, discrimination, and planning (Barkley and Greed, 2006; Greed, 1996; 2004; Moore, 2002; Wang and Huang, 2005; Weisman, 1992). Such issues concern not only spatial configuration and design, but also political, social, and cultural matters. In Canada, New Zealand, Australia, and the UK, the provision of public toilets for women was late, partial, and often only achieved through local and national civil campaigns (Andrews, 1990). Because of the biological differences (menstruation, pregnancy) between men and women; men have less to do in the toilet and can do it more easily (Simpson, 2000). Women take three minutes in the bathroom while men take a mere 83.6 seconds (Rawls, 1988). Moreover, according to Bombeck (1994), women take more time to get dressed and undressed in a confined space. The common problem in all these gender-related studies is summarized by Anthony and Dufresne (2007) and divided into four categories: (i) unequal restrooms in terms of size and number; (ii) inadequate sanitary conditions in women's restrooms; (iii) not being able to locate women's restrooms; and (iv) no women's restrooms at all. As stated above, the literature identifies many planning, design, and sociospatial aspects of public toilet provision and use in the 21 st century. In that sense, visiting a public toilet is not a simple deed to perform a bodily necessity, but is an essential act for connecting to social life and a reflection of land-use patterns.

Because of declining physical and biological abilities due to the aging process, (eg, more frequent urinary tract infections, irritable bowel syndrome, and chronic digestive illness) older people make multiple trips to the toilet (Barker and Mitteness, 1988) and need hand supports and an adjustable toilet seat. Anthony and Dufresne (2007) highlight that if there is a lack of availability of such public toilets for the elderly they are forced to stay at home or are hampered in daily activities. Regarding ability issues, the provision of public toilets is seen as a crucial determinant for the disabled to participate in society. Kitchin and Law (2001) reveal three critical themes in relation to the provision of public toilets for disabled people: (1) a lack of accessible toilets because of vandalism, and poor and limited provision; (2) poor toilet design (eg, steps, inadequate door size); and (3) misuse of toilets (eg, they are sometimes used as storage cupboards and/or are kept locked). As a result of these themes, disabled people exhibit constrained patterns of spatial behaviour and daily routines. Providing toilets for disabled people also provides parents with children more room than a standard stall, making it easier and/or possible for a stroller and/or other children to remain with the parent.

Reviewing the literature shows that there are various accessible design attempts, barrierfree projects, and inclusive models exploring the inclusion of these different and disparate groups and how to achieve their needs, demands, and expectations of public services (Afacan, 2012; Goldsmith, 1997; Hall and Imrie, 1999; Kitchin and Law, 2001). Some insight into the implications of design and policy practice for these groups can be listed as follows: urban developments for an aging population, where they have easy access to services (toilets, phones, ATMs) and public transportation; universally designed outdoor gardens and parks (including toilets) serving children and people with all types of impairment; government policies and laws for sustainable social development of public services and assistive technologies to 
support people with dementia in urban environments. Following the awareness raised by research on this subject, we argue in this paper that public toilet provision needs a close and detailed consideration regarding gender, disability, and age.

\section{Methodology}

The study was based on quantitative and qualitative data. The former was derived from statistical analyses of the structured interviews, in which participants were asked about their demands and needs while using public toilets. It encompasses important considerations for the social and physical aspects of public toilets. The latter was determined from observations of existing facilities and informal discussions after each interview, which dealt with participants' experiences regarding deficiencies in the current provision and desired design for future provision. These informal discussions elicited users' opinions so researchers could understand the challenges people face in using public toilets and explore expectations regarding good quality, inclusive, and healthy public toilets.

\subsection{Sample and site}

A total of 300 randomly selected people in the city centre of Ankara, Turkey, participated in the survey, including 100 adults under 65 years of age, 100 adults over 65 years, and 100 physically or visually disabled adults [the physically disabled people used wheelchairs $(n=30)$, crutches $(n=15)$, prostheses $(n=7)$, and canes $(n=8)$ as mobility aids, and the visually disabled people had total loss of sight $(n=22)$ and mild loss of sight $(n=18)$; table 1]. None of the under-65 cohort had any health problems, whereas $9 \%$ of the over- 65 cohort listed eye problems (eg, low vision, cataracts) and 33\% listed movement problems (eg, walking, rheumatism). None of the participants was in need of institutional care or had any mental disability. All participants participated in a structured interview and, to satisfy ethical requirements, signed a consent form.

The urban case-study site was chosen from the densest and most popular urban area in Ankara (the Kizilay-Sihhiye-Ulus region; $6 \mathrm{~km}$ long; figures 2 and 3), which contains welldeveloped infrastructures including different vehicular and pedestrian traffic patterns, access points to public transport, pedestrian facilities, parks, notable buildings such as embassies

Table 1. Demographic characteristics of the participants.

\begin{tabular}{|c|c|c|c|c|c|c|c|c|}
\hline & \multicolumn{2}{|l|}{ Adults } & \multicolumn{2}{|l|}{ Elderly } & \multicolumn{4}{|c|}{ People with disabilities physical visual } \\
\hline & \multirow[t]{2}{*}{ female } & \multirow[t]{2}{*}{ male } & \multirow[t]{2}{*}{ female } & \multirow[t]{2}{*}{ male } & \multicolumn{2}{|l|}{ physical } & \multicolumn{2}{|l|}{ visual } \\
\hline & & & & & female & male & female & male \\
\hline $\begin{array}{l}\text { Number of } \\
\text { participants }\end{array}$ & 58 & 42 & 45 & 55 & 26 & 34 & 24 & 16 \\
\hline Age (years) & $22-57$ & $24-58$ & $65-97$ & $65-90$ & $28-51$ & $24-49$ & $22-55$ & $26-54$ \\
\hline $\begin{array}{l}\text { Disability } \\
\text { status }\end{array}$ & - & - & $\begin{array}{l}\text { eye } \\
\text { problems } \\
(n=5) ; \\
\text { movement } \\
\text { problems } \\
(n=18)\end{array}$ & $\begin{array}{l}\text { eye } \\
\text { problems } \\
(n=4) ; \\
\text { movement } \\
\text { problems } \\
(n=15)\end{array}$ & $\begin{array}{l}\text { using a } \\
\text { wheelchair } \\
(n=13) ; \\
\text { using } \\
\text { crutches } \\
(n=7) ; \\
\text { using a } \\
\text { prosthesis } \\
(n=2) ; \\
\text { using a } \\
\text { cane } \\
(n=4)\end{array}$ & $\begin{array}{l}\text { using a } \\
\text { wheelchair } \\
(n=17) ; \\
\text { using } \\
\text { crutches } \\
(n=8) ; \\
\text { using a } \\
\text { prosthesis } \\
(n=5) ; \\
\text { using } \\
\text { a cane } \\
(n=4)\end{array}$ & $\begin{array}{l}\text { no vision } \\
(n=12) ; \\
\text { low vision } \\
(n=12)\end{array}$ & $\begin{array}{l}\text { no vision } \\
(n=10) \\
\text { low vision } \\
(n=6)\end{array}$ \\
\hline
\end{tabular}




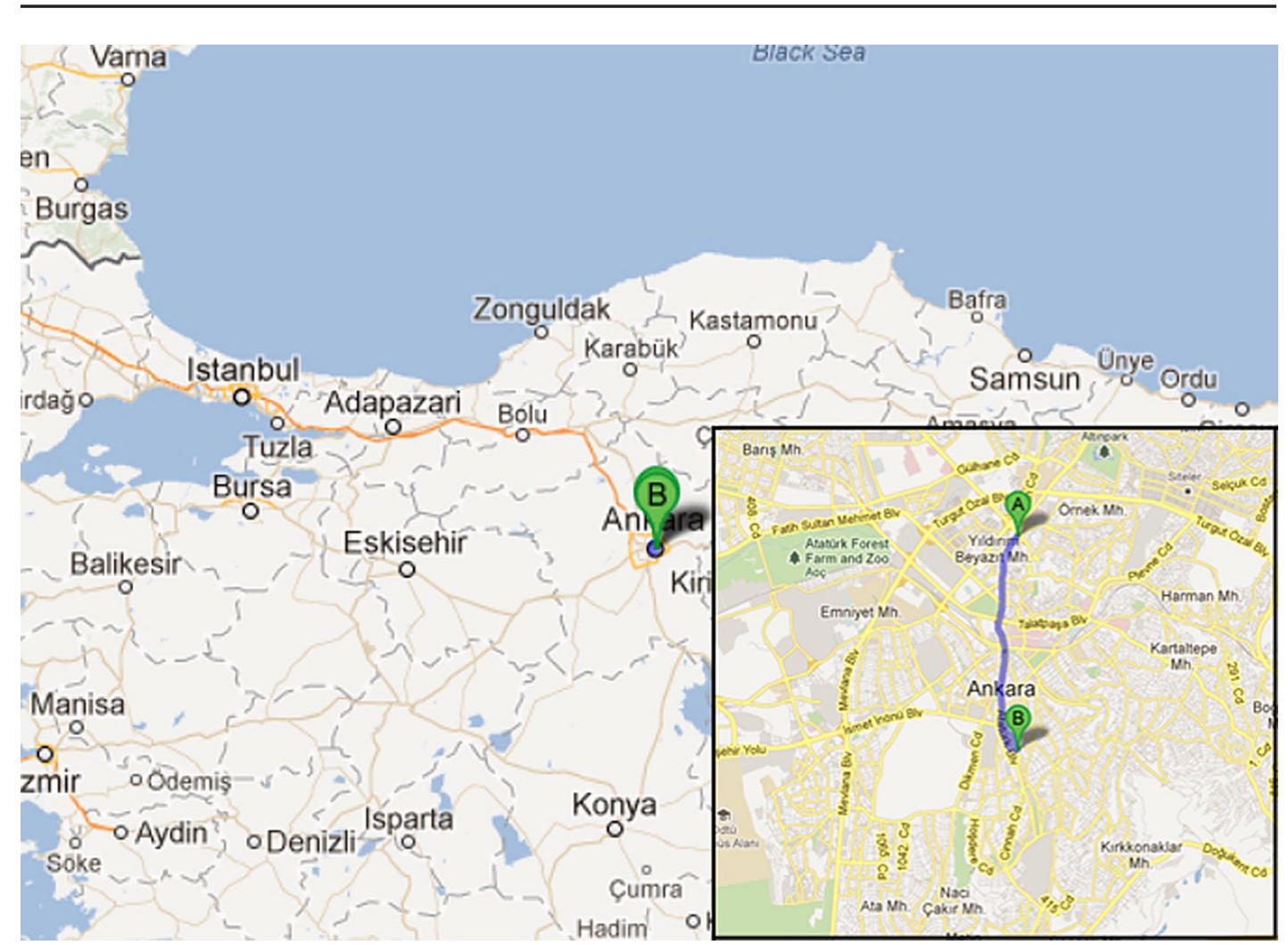

Figure 2. [In colour online.] Map showing Ankara, the capital of Turkey.

and plazas, and other buildings and urban facilities. The main reason for selecting this site was due to its strategic policy dimension for the provision of public toilets. Ankara is the capital city of Turkey, where government departments, agencies, and professionals provide major input into toilet provision decision making, and thus should be versed in eliciting user requirements, determining possible physical and social problems, and suggesting design solutions. Moreover, the site is in the heart of the city, where a mixture of people of different abilities, sizes, ages, educational backgrounds, incomes, and health issues can be found at any given time.

\subsection{Procedure}

First, fourteen public toilets (see figure 3) were examined, photographed, and analyzed by the authors to determine what actually exists in the area. Next, the participant survey was conducted by the authors and by third-year and fourth-year interior architecture student volunteers. The fieldwork (examination and survey) lasted five months, where the researchers visited each public toilet on weekdays between $10 \mathrm{am}$ to $2 \mathrm{pm}$ and on weekends between $10 \mathrm{am}$ to $6 \mathrm{pm}$, when the highest use usually occurs. A survey instrument with a comprehensive list of fiftyfive items was developed to gather data. It was based on a structured questionnaire format with closed-ended questions. The questions were grouped into six categories with reference to Burton and Mitchell's (2006) streets-for-life principles: familiarity, legibility, distinctiveness, accessibility, comfort, and safety. The streets-for-life concept is a mechanism for achieving inclusive design goals at a neighbourhood scale and enabling outdoor environments to be as dementia friendly as possible (Burton and Mitchell, 2006).

Familiarity in urban environments helps to reduce confusion and maintain the independence of the elderly, and positively influences their physical activity (Booth et al, 2000). Legibility helps people understand where they are and where they want or need to go (Burton and Mitchell, 2006). Distinctiveness in urban spaces full of activity attracts people (even those 


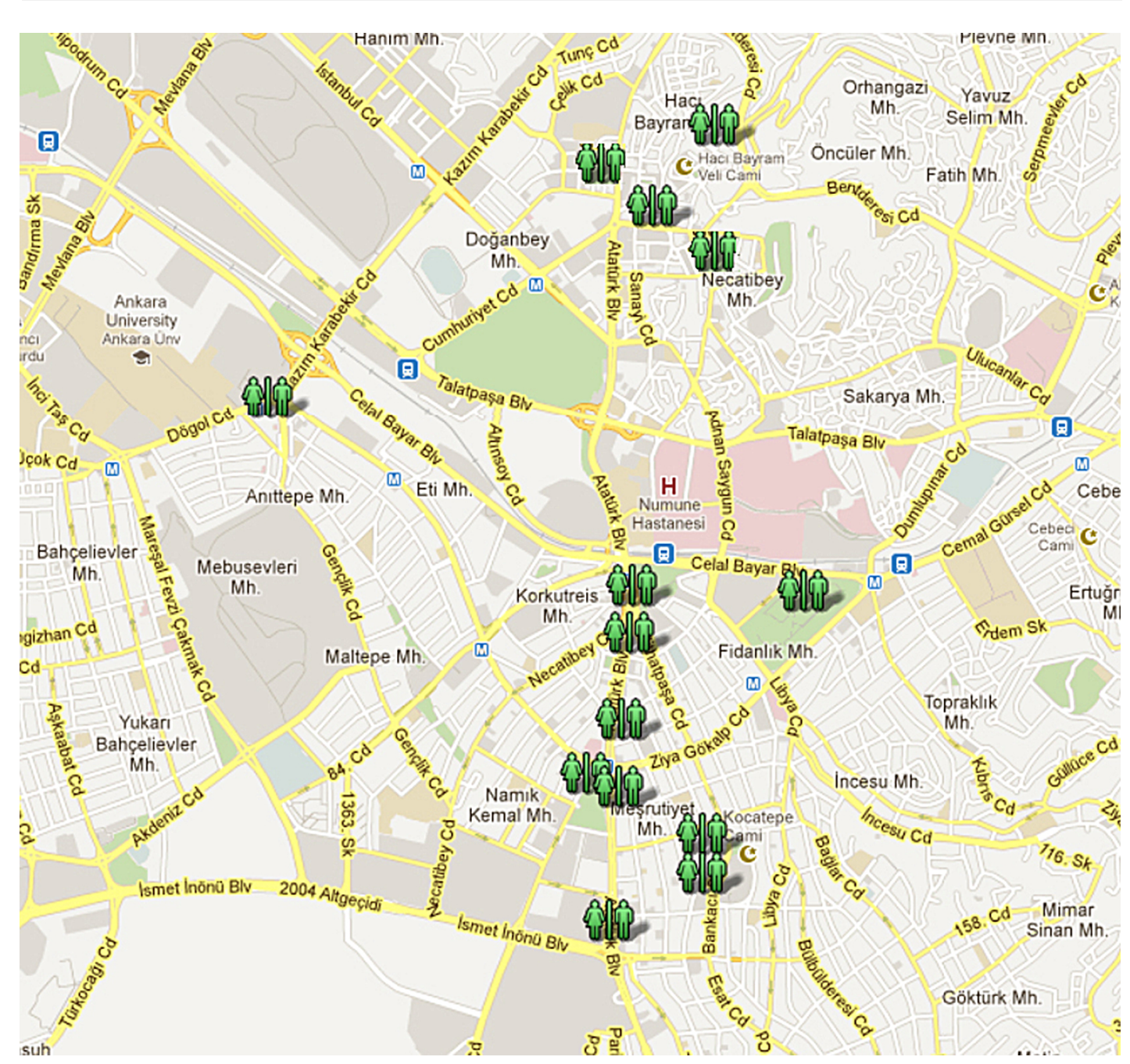

Figure 3. [In colour online.] Map of the study site, the Kizilay-Sihhiye-Ulus region of Ankara, Turkey.

with dementia) and, as related to public toilet provision, encourages everyone to experience the toilets. Accessibility is defined as the extent to which people, regardless of their ability, are enabled to visit, reach, use, and access all facilities safely and independently. According to Imrie (2000), comfort in a built environment is associated with calm and welcoming feelings, which is essential for a public toilet. Safety refers to the extent to which people can use the urban environment without fear of falling, being attacked, or run over. These six principles also correspond to the issues of public toilet access highlighted by Gershenson and Penner (2009), that is, to make toilet spaces more liveable by taking them beyond their symbolic, social, and material complexities to a new level of acceptance and even enjoyment.

During the survey, users were asked to rate the importance level of each item listed under each of the six principles on a scale of 1 to 5 ( 1 being the least important and 5 the most important), and to mark the appropriate boxes to identify the importance of each feature in understanding, using, and experiencing a toilet environment. The data were collected during face-to-face surveys with people in a public seating area. The aim of the study and a brief summary of the procedure were explained at the beginning of the data-collection process, and items that may have been unclear were also explained as part of the questionnaire. Further information was obtained through an unstructured interview, which discussed the results of the questionnaire in a more comprehensive way. To avoid any biases, participants were not allowed to listen to others being surveyed. 


\section{Results}

The findings are elaborated in three sections below. The first section deals with photographic and observational data, and the last two sections present the statistical analyses. The participants' ratings of the fifty-five items were analyzed using the statistical package for the social sciences 10.1. By means of these analyses, frequency distributions, cross-tabulations, and $\chi^{2}$ tests for independence were calculated. The $\alpha$ coefficient for all items is 0.9202 , suggesting that the items have a relatively high internal consistency. Factor analysis was also conducted to investigate correlated variables that may work together to form an inclusive public toilet. Since a ratio as low as five subjects per variable is appropriate for distribution (Bentler and Chou, 1987), the study sample size (300 participants) is considered adequate in terms of sample representativeness and estimate accuracy.

\subsection{What actually exists: analyzing the problems}

From the observations of fourteen toilets in the defined area, the authors identified problems with reference to Burton and Mitchell's (2006) streets-for-life principles and categorized them under physical and social barriers that hinder the use of toilet facilities. The physical problems with toilets are related mostly to accessibility, usability, ease of manipulation, and wayfinding. Among these, accessibility is the most critical issue. Toilet entrances often have poorly constructed steps and inadequate handrails (figure 4). None of the entrances to the toilets is at ground level. Further, the toilets either have no ramp or the slope of the ramp is difficult or impossible for a wheelchair, walking frame, and/or pushchair. In general, steps are not clearly marked and have no contrasting colours to make navigation easier. Risers are not uniform and treads are not wide enough. Another accessibility problem concerns insufficient widths of entrances and/or stall doors for manoeuvering and passing (figure 5).

The main reasons for usability problems are as follows: insufficient or poorly designed sanitary equipment, such as washbasins, toilets, flushing mechanisms, and urinals. Most of the washbasins and toilets are not located at heights accessible to everyone. Many times

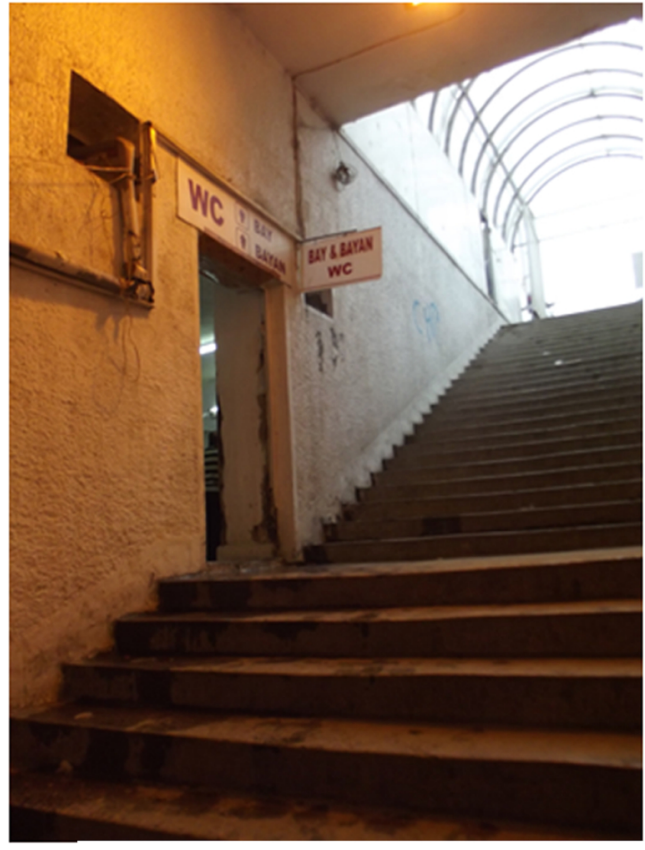

(a)

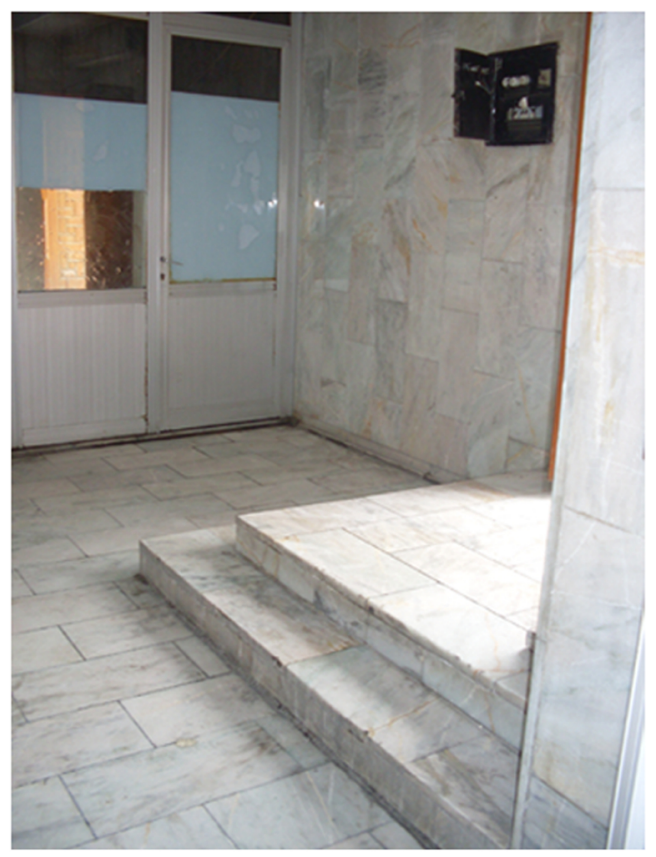

(b)

Figure 4. [In colour online.] Two examples of public toilets accessed by steps: (a) a long, steep flight of steps with no handrail; (b) fewer shallow steps but no ramp or handrail. 


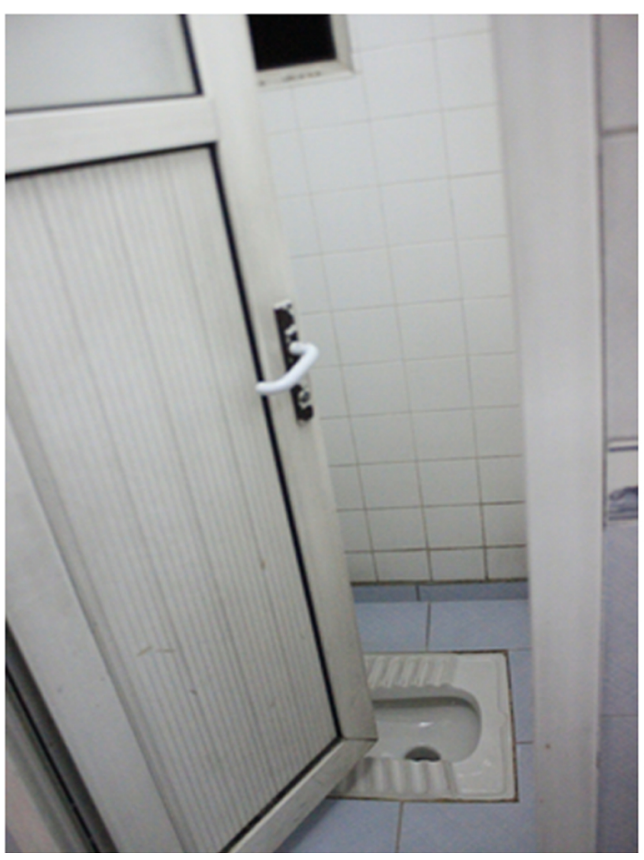

(a)

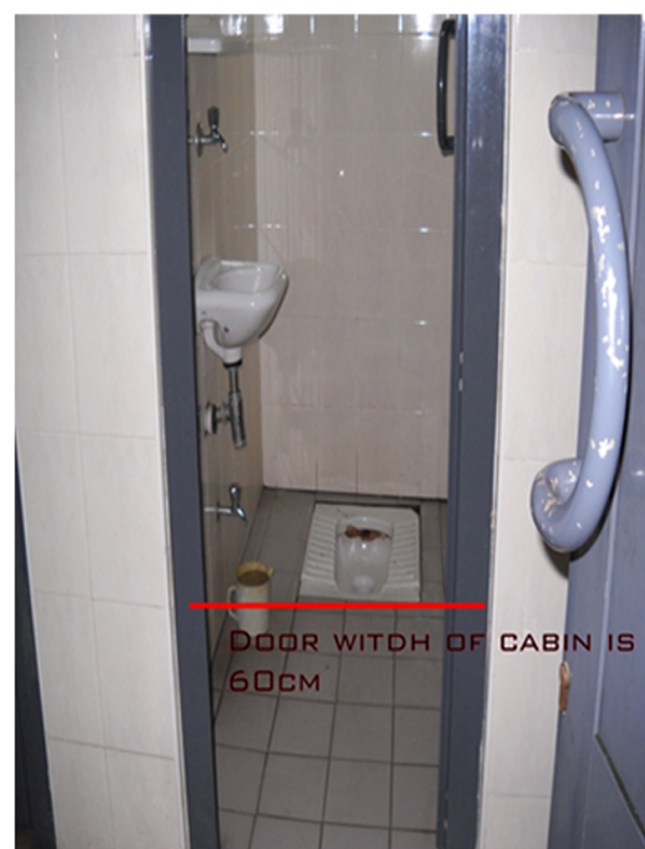

(b)

Figure 5. [In colour online.] Two examples of public toilets with inadequate access to stalls: (a) insufficient manoeuvring space; (b) narrow door.

paper-towel dispensers or hand dryers are so high that residual water runs down one's arms reaching for them! Few are accessible for children, so parents have to lift their children up over the sink with one hand and turn on the tap with the other (which usually gets their clothes wet from water accumulation on the counter and/or from the tap itself because of the awkward position). In some of the public toilets examined, women's toilets are fewer in number and smaller in size compared with men's or there are no toilets for women or the disabled at all. Only three of fourteen toilets include a toilet for the disabled and only one has a baby changing station and feeding room. None has a family room. Family-friendly restrooms are essential for enhancing the quality of city life and allowing parents and their children to use the toilet at the same time in a convenient way (Anthony and Dufresne, 2007). Even adding a stool so children can reach the sinks on their own would improve the public toilet experience.

All toilets have poor lighting, ventilation, and piping conditions, both aesthetically and functionally (figure 6). The floor materials in eight of the toilets are slippery in all weather conditions and/or in winter. Further, most fixtures, door handles, and stall locks are difficult to operate; for many of them, so many attempts are necessary that the motion causes fatigue and/or pain.

Disorientation, confusion, anxiety, and fear of being attacked are the observed social problems in these fourteen toilets. Underground toilets pose many safety issues, particularly for women, children, the elderly, and the disabled (figure 7). Because of the poor lighting, these toilets cause feelings of fear and fear of being attacked, especially at night. Many toilets display broken and uneven pavements, which are hazardous for young children, the elderly, and people with physical and visual disabilities. Furthermore, the signage systems for most of the toilets (ten of fourteen) are not well designed, which causes disorientation and confusion (figure 8). Providing accurate and intuitively understandable directional guidance is important to minimize confusion (Preiser and Smith, 2010). Maps, directions, and signs can be difficult for an older person to understand, regardless of mental capacity; for this 


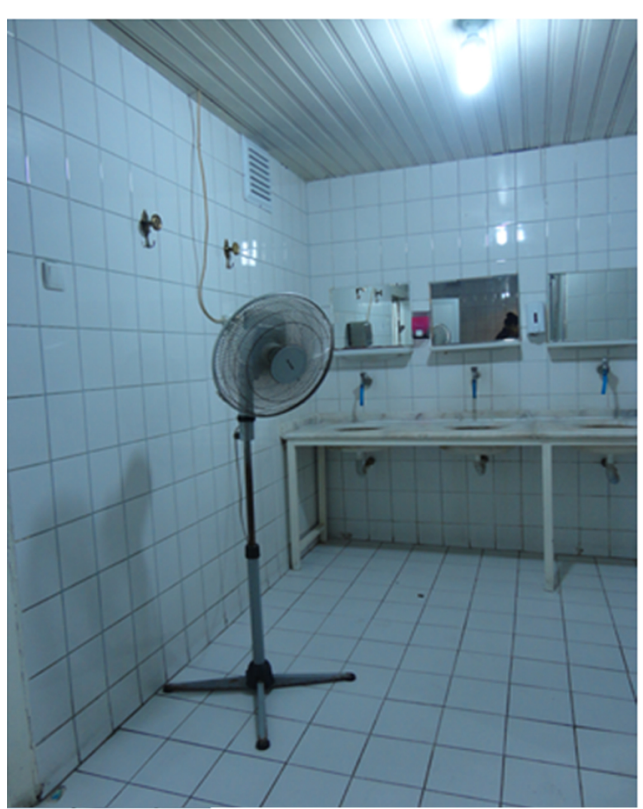

(a)

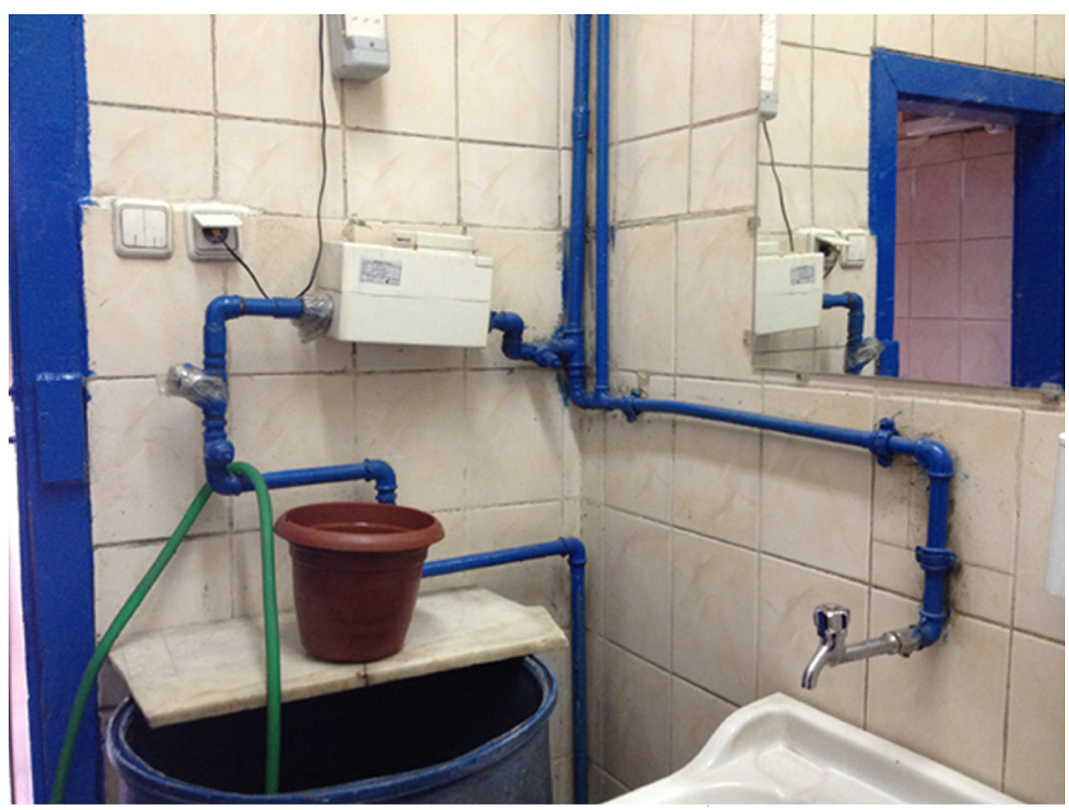

(b)

Figure 6. [In colour online.] Examples of public toilets with (a) poor lighting and ventilation, (b) poor piping conditions.

reason, some people use landmarks and environmental features for navigation, such as a letterbox or a favourite tree.

Health issues are also observed in these toilets. Anyone using ten of fourteen toilets is put at a significant risk because of nonhygienic conditions. All users deserve hygienic and clean public toilets, because of the associated high risks of infection, due to menstruating women, parents changing diapers, people with urinary and faecal incontinence, the elderly, and people using wheelchairs (Armstrong and Scott, 1992; Greed, 2009). 


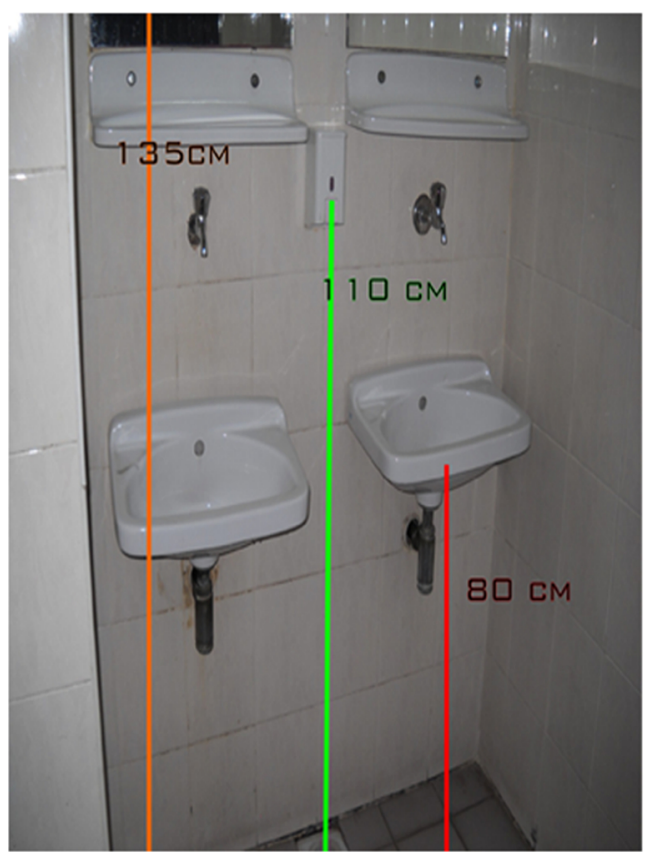

(a)

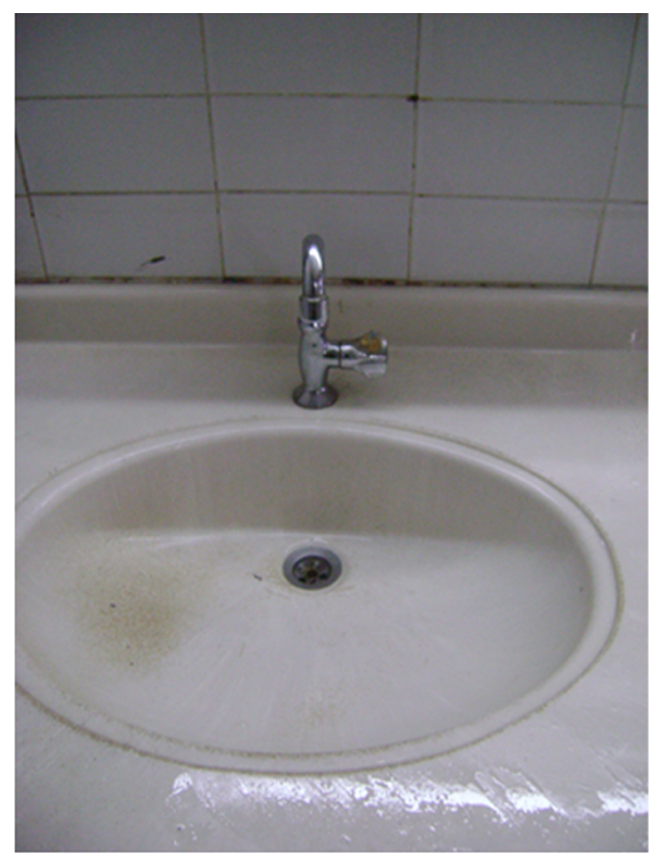

(b)

Figure 7. [In colour online.] Two examples of toilets with safety issues.

\subsection{Toilet facilities people require most: developing inclusive public toilet factors}

Before carrying out factor analysis, the authors reviewed the survey instrument to determine whether there were any items creating floor or ceiling effects, where items at the extreme ends of the scale should be eliminated. A five-factor scale was used in the study, and thus items below 1.5 and above 4.5 would be at the extreme ends, but no items matched these criteria. Next, the strength of the correlations among the survey items was calculated through exploratory factor analysis, which helped identify common issues and exclude unrelated ones. Pearson product-moment correlations of the response scores were calculated and a correlation matrix was constructed, in which all the response items were illustrated in rows and columns of statistical relationships with a correlation score. Items having a correlation score lower than 0.30 were not considered in the analysis; for a useful statistical approach a correlation coefficient of 1.00 indicates a perfect association between two variables (Argyrous, 2005). In the study, ten correlations between item response scores were lower than 0.30 , so they were eliminated.

The study defined factor loadings in excess of 0.55 as suitable and factor loadings below 0.55 as unsuitable. The total variance of factors was also calculated. "Total variance shows all the factors extracted from the analysis along with their eigenvalues, the percentage of variance attributable to each factor, and the cumulative variance of the factor" (Mieczakowski et al, 2010, page 138). Factor analysis resulted in a six-factor solution that accounted for $59.188 \%$ of the total variance. Forty-five items had $59.188 \%$ variances in common, so they correlated highly with seven common themes; each theme was considered to be a factor.

Factor 1 (legible use with a minimum confusion and disorientation) is mostly defined by visibility aspects. The variables of this factor include providing mental maps, signs, appropriate lighting features, and inclusive directional guidance to encourage toilet use without fear of getting lost (table 2). Although toilets are associated with dirt, germs, and the remains of other people's unsavoury habits (Greed, 2003), their location and visibility within the existing urban form is critical. Brown-May and Fraser (2009) explain the process of placing public toilets during the late 19th and early 20th centuries as follows: "whereas the 


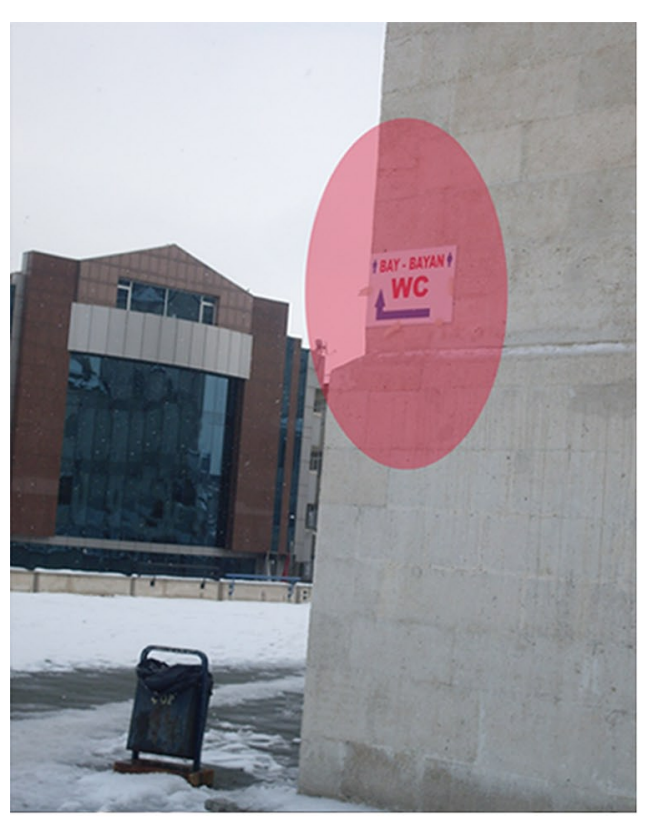

(a)

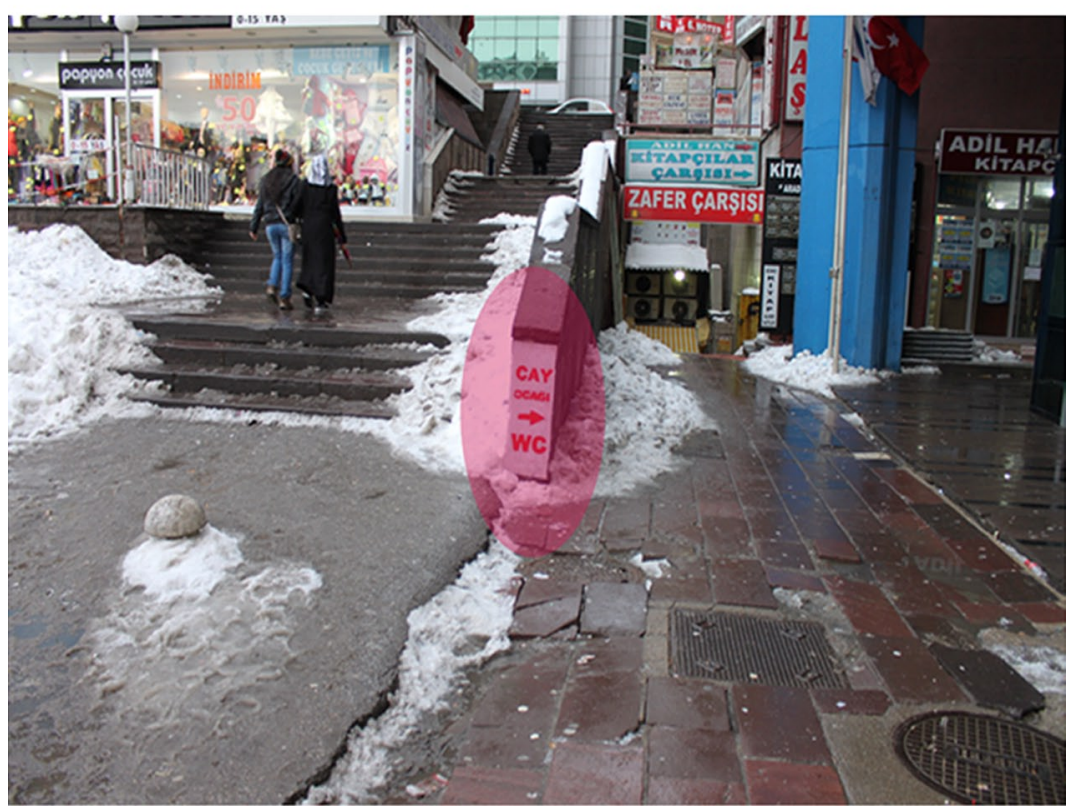

(b)

Figure 8. [In colour online.] Two examples of toilets with inadequate signs.

sight of public toilets themselves was once as the back-street nuisances they sought to allay, they eventually found a place on city streets as essential and practical sites of containment" (page 87). Sixty-eight of 100 adults under 65 years of age, eighty-three of 100 adults over 65 years, and all the disabled participants, regardless of impairment, complained about nonvisible entrances to the toilets and their inconsistent location within the urban form, which cause disorientation and/or confusion. Most of the elderly cohort (seventy of 100) and all participants with a visual disability highlighted the significance of clear and readable signs, which are most effective when they are placed perpendicular to walls. 


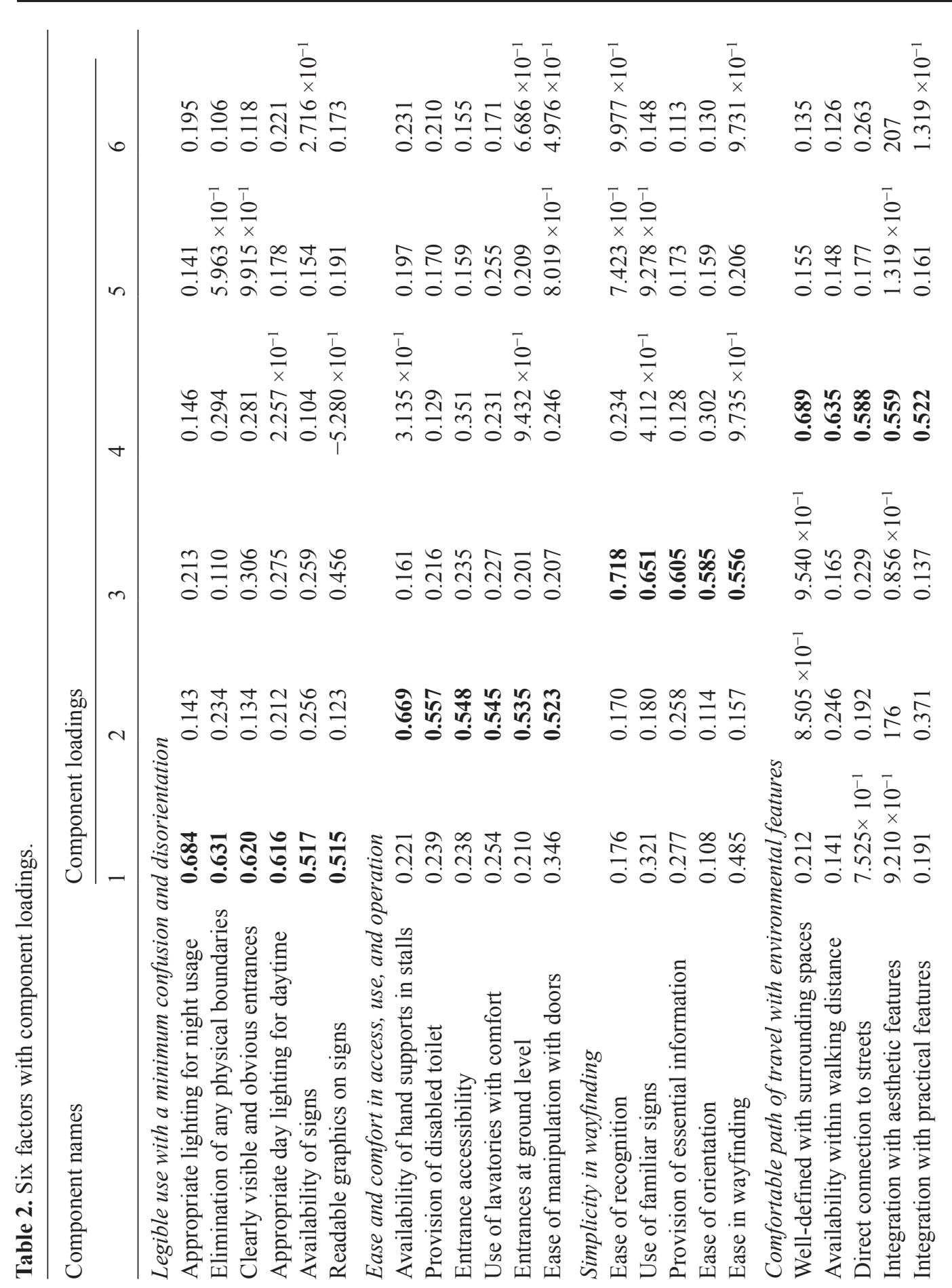




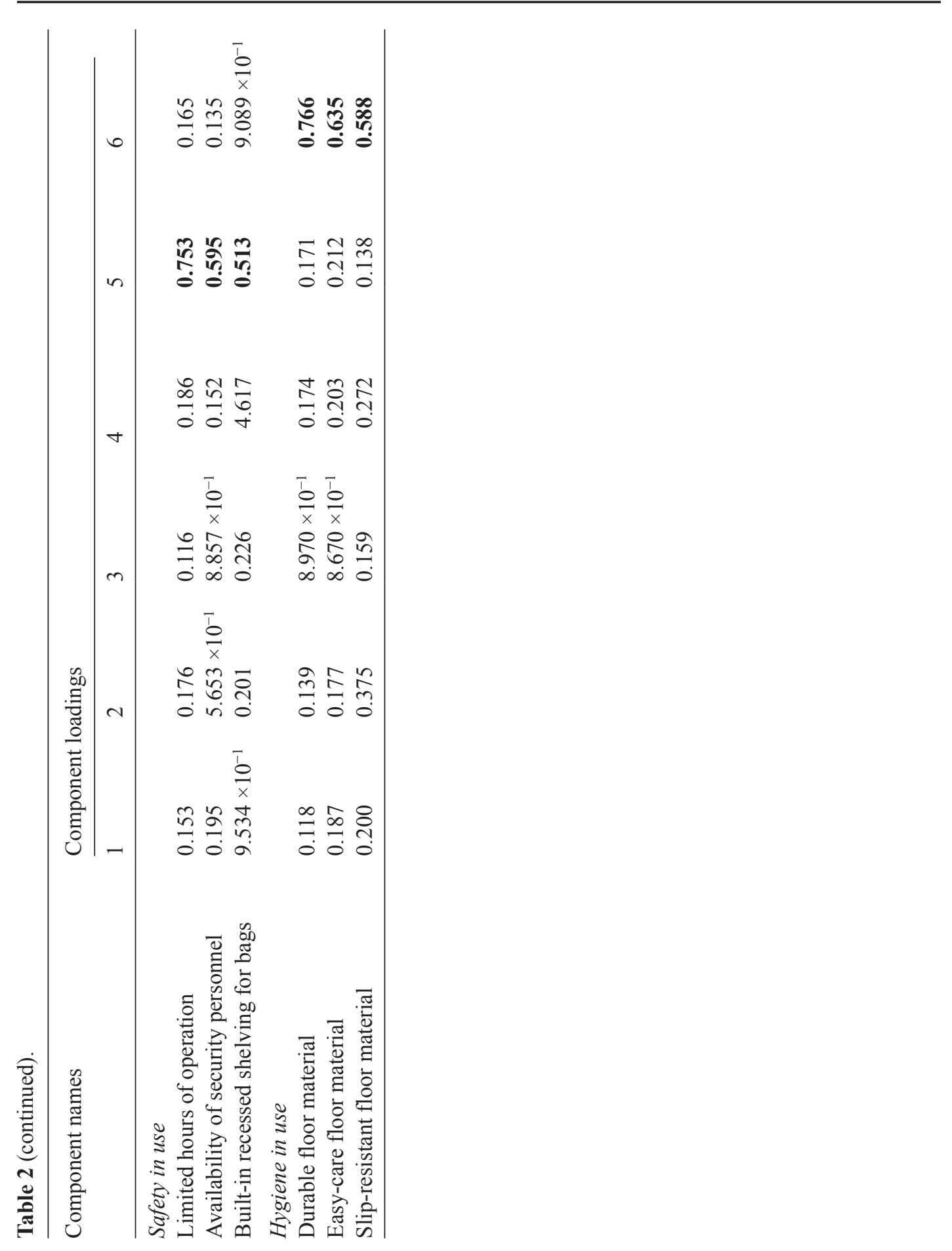


Factor 2 (ease and comfort in access, use, and operation) is defined as having comfortable and independent access to toilets and their facilities. As Kitchin and Law (2001) find, and also this study, the most commonly stated accessibility problem is that entry to toilets is prevented by steps. In our study, eight of fourteen toilets have level changes at the entrances to the stalls, and this is problematic for people with rheumatoid arthritis (who find it difficult to lift their feet), for people with visual disabilities (who struggle to see the steps), for pregnant women (who may experience both of the aforementioned issues), and for parents who may be using toilets with their children. Women are more in need of public toilets than men, because they are more likely to be out grocery shopping or running errands and are often accompanied by children and/or the elderly (Greed, 1996; Nemeth, 2009). Most participants (236 of 300) stated that Ankara has few public toilets for disabled people; even those provided are usually locked or used as storage facilities. There is also a lack of comfortable facilities; fifty-three of sixty physically disabled participants and sixty-five of 100 elderly participants emphasized that they could not use the fixtures without fatigue.

Factor 3 (simplicity in wayfinding) is defined by five variables related to familiarity. According to Imrie (2000), the loss of familiar street markers or additions of new ones make people feel vulnerable in a built environment. Forty-five of 100 people under 65 years of age, seventy-two of 100 elderly, and sixty-six of 100 disabled participants, regardless of their impairment, complained about difficulty understanding their surroundings. Most of the adults under 65 years of age (sixty-six of 100) stated that they prefer using toilets in cafés, restaurants, and shopping malls because they are easy to find, more convenient, and also well maintained and clean. These toilets are generally throne-style rather than squat toilets. Local authorities should ensure safe, accessible public toilets at important points in the city centre. In Turkey, while toilet provision has been legislated into the disability policy, it has not been incorporated into the main urban development policy (Ministry of Administration for Disabled, 2005).

Factor 4 (comfortable path of travel) is defined by five variables, which are closely related to easy use of the urban environment without physical or mental distress. Finding ways to reduce expenditure of effort and minimize repetitive actions at all scales of the environment is essential. Michael et al (2006) highlight that a comfortable path of travel in a built environment positively influences active ageing and elderly people's decision to live in a particular neighbourhood. In addition to public toilets, nearby destinations, a hierarchy of streets, public seating, and places to stop and rest while walking are important to everyone, not only the disabled and elderly (Afacan and Afacan, 2011). An accessible toilet is not enough; the conditions of footpaths and roadways should also be improved through aesthetic and practical environmental features which can reflect local character and contribute to a city's identity in a variety of spaces (high-rise buildings, parks, historic structures). Improvements can also be made through colour, interesting and appropriate construction materials, street furniture, and installing multi-use areas (play areas and recreation grounds).

Factor 5 (safety in use) is the result of the previous four criteria. If an urban environment is familiar, legible, distinctive, accessible, and comfortable, then the environment is safe and there are likely to be no worries about being attacked or of falling. Inadequate public toilet provision can limit people's participation in urban life (Michael et al, 2006), whereas welldesigned streets and open spaces with public toilets encourage walking and cycling and can make our environment safer. Most female participants (102 of 153) and most of the elderly (60 of 100) placed high importance on the availability of security personnel because they feel unsafe in a toilet facility, particularly at night: "public restrooms provide convenient hiding spots for criminals" (Anthony and Dufresne, 2007, page 277). 
Factor 6 (hygiene in use) is closely related to the material choices made during the design stage and to the overall approach during the maintenance and occupation stages. Durable, easy-care and slip-resistant flooring is a basic consideration and can mitigate unpleasant sights and smells. All the female participants in the study stated that the toilets do not take feminine hygiene needs into consideration, a statement supported by Anthony and Dufresne (2007, page 274): "Public restroom deficiencies affect women and children even more adversely" than for men. In Turkey, squat toilets are more common than throne-style and pose more risk if the toilet facilities are not cleaned regularly. Rather than considering this a cleaning and health issue, tradition is an important factor in the use of such toilets in Turkey relating to how people use public conveniences according to sociocultural appropriateness. This issue is discussed in detail in section 7. Feminine hygiene needs are also an issue, and all the female participants in the study stated that toilet facilities do not take these needs into consideration. This is supported by Anthony and Dufresne (2007, page 274): "Public restroom deficiencies affect women and children even more adversely" than they do for men. In the Turkish context, if sanitary napkins are not available from a dispenser, a woman must ask an attendant for one. According to Anderson (2009), asking for sanitary napkins is an issue of privacy rather than hygiene: "the most logical reason for asking [for a] sanitary napkin is so that one can attend to one's menstrual activities ... the moment one requests a sanitary napkin, this experience become public" (Anderson 2009, pages 97-98).

Consideration of these six factors can promote cleaner, safer, and more accessible and comfortable toilet provisions for everyone. However, for good health and public safety it is also important to understand how toilet demands, needs, and expectations differ among user groups. In the next section we elaborate on this issue.

\subsection{How demands, needs, and expectations change among diverse user groups}

We utilized ANOVA analyses with Bonferroni post hoc comparisons on each factor scale score and calculated the $F$-ratio to analyze whether the scale means of the user groups differ significantly from each other. Statistically significant differences were found between user groups in factors 1 and 4 but no statistically significant differences were discovered between the user-group scale means in the other four factor-score scales. For factor 1 (legible use with minimum confusion and disorientation), the elderly participants differed significantly from the rest of the group. Due to the ageing process, the elderly experience deterioration in their physical abilities and struggle to interpret information supplied by signs and graphics. Moreover, because of a decline in their cognitive abilities, most elderly participants (68 of 100) found clearly visible and obvious entrances more important than other users. The response means of the physically disabled participants were similar to the elderly adults regarding the six variables of factor 1 ; however, most visually disabled participants (35 of 40) specifically found items related to appropriate lighting more important. Further, because most of the services within Ankara's city centre are not consistent in signage methods, such as colour contrasts, Braille markings, large-print readouts, or audible and tactile feedbacks, twenty-six of forty participants with visual limitations had difficulties determining the location of a public toilet and how to access it.

The mean scores of factor 4 (comfortable path of travel with environmental features) indicated a statistically significant difference between user groups. Compared with the adults under 65 years of age, disability status and participant age affected the importance level of easy use of a travel path. All elderly participants emphasized the importance of the availability of a public toilet within walking distance of critical points in the city centre (mean $=4.35$ ). Because visually disabled users sometimes use their hands to touch and sense environmental features, thirty-five of forty participants with visual disabilities found landmarks and environmental features, such as a letterbox, important on their path of travel. For wheelchair 
participants and participants with crutches, a direct connection to streets was an important variable for public toilet use. Furthermore, there were statistically significant differences between female and male adults regarding the following variables: appropriate lighting for night use; availability of security personnel; built-in recessed shelving for bags; comfortable use of lavatories; integration with aesthetic features and easy-care floor material. Physically and visually disabled male and female participants did not differ statistically regarding the six factor scales; however, elderly male and female participants differed significantly regarding the following variables: well-defined location with surrounding space; use of familiar signs; provision of disabled toilet; ease of manipulation of doors; operation of fixtures with minimum force; availability of signs; appropriate lighting for night use and availability of security personnel.

\section{Discussion and conclusion}

The social and physical roles of public toilets in city life are undeniable; they are the reflection of our culture and civilization (Anthony and Dufresne, 2007). Although public toilets are critical components of urban environments, they are defined as marginal, and tend to be a visiting point of last resort. The appearance of the six inclusive public toilet factors in a set of correlations indicates that achieving a successful public toilet solution necessitates considering each factor with its variables simultaneously. As Greed (2003) argues, to cut costs, public toilets are seen as last-priority urban spaces, and this also applies in Turkey.

The findings of this study can be discussed from the three perspectives: the design domain (the architects' and planners' points of view); the political domain (policy makers' points of view), and the sociocultural domain (in terms of practices of users). One of the key issues regarding improving public toilet use in all countries is the urgency of reexamining traditional toilet use. Toilets should be analyzed regarding changing user profiles; in the twenty-first century, life expectancy is high and needs are more varied. Another key design issue for maximizing function and comfort in a public toilet is indoor environmental quality, such as appropriate light and ventilation for all users.

Regarding the policy domain, according to Greed (2009), there is a need for strategic, city-wide, and policy-level approaches to solve problems in public toilet provision and management. Considering the significance of public toilet use, traditional planning strategies should be reviewed and updated; toilets should be treated as an integral part of city planning. All government policies, departments, agencies, and professionals should elicit user requirements in detail and enlist representatives for toilet decision making. Toilet providers should be knowledgeable about their products and well equipped, as well as aware of the issues around public toilet provision. From the perspective of the sociocultural domain, public toilet provision and usage could be linked to culturally informed practices. For example, in a country like Turkey, where religion and the notion of secularity is a contested issue, restroom fixtures embody and reflect this contention. As using Pierre Bourdieu's concept of 'habitus' (1979/2007), exploring toileting habitus (Inglis, 2001) helps us to understand how Turkish people use toilets and to discuss why squat toilets are common.

Traditionally, Turkish homes had toilet facilities where the user crouched over a basin with a hole in it that led to a pit, rather than sitting on a bowl (Gurel, 2008). The throne-type toilet was considered by many people as a European mode of bodily practice and an undesirable way of using toilets (Gurel, 2008). In time, as European notions of hygiene became more accepted, squat toilets were perceived as dirty, outmoded, and even uncivilized, and thronestyle toilets were incorporated into domestic and urban life (Gurel, 2008). Although notions of modernization and Westernization in the Turkish context have increased the use of thronetype toilets, the issue of the sociocultural appropriateness of squat toilets in Turkey still has a great impact on the physical aspects of public toilets. In that sense, what shapes public toilet 
provision in Turkey is not simply a functional response to a physical need, but a cultural issue challenged by user habits and expectations.

How the design, political, and sociocultural domains work with each other is crucial to supporting an inclusive urban life and answering questions on how we think about and understand public toilets. These domains are not mutually exclusive. Well-structured local governments must seek and apply user input and hire professionals who are knowledgeable about the design, usage, and access of public toilets, to ensure safe, healthy, and even enjoyable toilet experiences. As Greed (2009) stated "promoting a culture of cleanliness and care would result in better, more accessible provision for everyone" (page 45). In that respect, an inclusive public toilet provision matters to urban life because it is necessary for healthy city planning, low levels of disease, a high degree of social participation, and sustainable development.

In addition to the factors in this study, architects, planners, policy makers, governments, municipalities, and all related bodies should consider sensory experiences, sociocultural appropriateness, and psychological and behavioural issues. When public toilets are well designed, managed, and maintained, they can yield healthful and accessible environments for all people and embody a vision of positive and equal human participation in urban spaces.

This study has some limitations, such as the sample size and the Turkish context. Future studies could include larger samples with cross-cultural studies and/or work with governments to adapt new codes and standards for public toilets and actively engage toilet-provision decision-making policies.

\section{References}

Afacan Y, 2012, "Achieving inclusion in public spaces: a shopping mall case study", in Designing

Inclusive Systems Eds P Langdon, P J Clarkson, P Robinson, J Lazar, A Heylighen (Springer, London) pp 85-93

Afacan Y, Afacan S O, 2011, "Rethinking social inclusivity: design strategies for universally designed sustainable cities" Proceedings of the Institute of Civil Engineering-Urban Design and Planning 164 93-107

Aker A, Tasdemir M, 2010 Public Toilets in Terms of the Public Health (Sage, Istanbul)

Anderson J, 2009, "Bodily privacy, toilets, and sex discrimination: the problem of 'manhood' in a women's prison" Ladies and Gents: Public Toilets and Gender Eds O Gershenson, B Penner (Temple University Press, Philadelphia, PA) pp 35-48

Andrews M, 1990, "Sanitary conveniences and the retreat of the frontier: Vancouver, 1886-1926" BC Studies 87 3-22

Anthony K H, Dufresne M, 2007, "Potty parity in perspective: gender and family issues in planning and designing public restrooms" Journal of Planning Literature 21 267-294

Approved Document M-Access to and Use of Buildings, 2004, incorporating 2010 and 2013 amendments, http://www.planningportal.gov.uk/uploads/br/ BR_PDF_AD_M_2013.pdf

Argyrous G, 2005 Statistics for Research (Sage, London)

Armstrong L, Scott A, 1992 Whitewash: Exposing the Health and Environmental Dangers of Women's Sanitary Products and Disposable Diapers (HarperCollins, Toronto)

Aspinall P, Ward-Thompson C, Alves S, Sugiyama T, 2010, "Preference and relative importance for environmental attributes of neighborhood open space" Environment and Planning B: Planning and Design 37 1022-1039

Atasoy N, 2000 Otağ-I Hümayun: The Ottoman Imperial Tent Complex (MEPA, Istanbul)

Barker J C, Mitteness L S, 1988, "Nocturia in the elderly" The Gerontologist 28 99-104

Barkley M, Greed C, 2006, "British standards revisions: more toilets for women and better toilets for all" Bathroom Today 2 42-43

Barton H, Tsorou C, 2000 Healthy Urban Planning (Spon, London)

Bentler P M, Chou C P, 1987, "Practical issues in SEM" Sociological Methods and Research 16 $78-117$ 
Bichard J, Hanson J, Greed C, 2004 Inclusive Design of Away from Home (Public) Toilets in City Centres: Pilot Study, Clerkenwell, London VivaCity 2020 EPSRC Research Report, University College, London

Bombeck E, 1994, "It's a fact: women designed to spend time in restrooms" San Diego (CA) Union Tribune 11 March, page 2

Booth M L, Owen N, Bauman A, Clavisi O, Leslie E, 2000, "Social-cognitive and perceived environment influences associated with physical activity in older Australians" Preventive Medicine 31 15-22

British Standard BS8300 2010 Design of Buildings and their Approaches to Meet the Needs of Disabled People - Code of Practice (BSI Standards Publication, London)

Brown-May A, Fraser P, 2009, "Gender, respectability, and public convenience in Melbourne, Australia 1859-1902", in Ladies and Gents: Public Toilets and Gender Eds O Gershenson, B Penner (Temple University Press, Philadelphia, PA) pp 75-90

Burton E, Mitchell L, 2006 Inclusive Urban Design: Streets for Life (Elsevier, Oxford)

Ersoy M, 1989, "The relationships between central and local governments in Turkey" METU Journal of Architectural Faculty 9 45-66

Ersoy M, 1999, "Local government finance in Turkey" METU Studies in Development 26 75-97

Gershenson O, Penner B (Eds) 2009 Ladies and Gents: Public Toilets and Gender (Temple University Press, Philadelphia, PA)

Goldsmith S, 1997 Designing for the Disabled: The New Paradigm (Architectural Press, London)

Greed C H, 1996, "Planning for women and other disenabled groups, with reference to the provision of public toilets in Britain" Environment and Planning A 28 573-588

Greed C H, 2003 Public Toilets: Inclusive Urban Design (Architectural Press, Oxford)

Greed C H, 2004, "Public toilets: the need for compulsory provision" Proceedings of the Institution of Civil Engineers-Municipal Engineers 157 77-85

Greed C H, 2005, "Overcoming the factors inhibiting the mainstreaming of gender into spatial planning policy in the United Kingdom" Urban Studies 42 1-31

Greed C H, 2009, "The role of the public toilet in civic life", in Ladies and Gents: Public Toilets and Gender Eds O Gershenson, B Penner (Temple University Press, Philadelphia, PA) pp 35-48

Gulluce I, 2004 Problems of the Local Governments and Solutions for Those Problems (Alfa Press, Istanbul)

Gurel M O, 2008, "Bathroom as a modern space" The Journal of Architecture 13 215-233

Hall P, Imrie R, 1999, "Architectural practices and disabling design in the built environment" Environment and Planning B: Planning and Design 26 409-425

Hanson J, Bichard J, Greed C, 2007 The Accessible Toilet Resource, http://eprints.ucl.ac.uk/4847/

Help the Aged, 2007 Incontinence and Older People: Is There a Link to Social Isolation?, http://www.ageuk.org.uk/documents/en-gb/for-professionals/research/ incontinence\%20and\%20 older\%20people\%20(2007)_pro.pdf?dtrk=true

Imrie R, 2000, "Disability and discourses of mobility and movement" Environment and Planning A 32 1641-1656

Inglis D, 2001 A Sociological History of Excretory Experience: Defecatory Manners and Toiletry Technologies (Edwin Mellen, Lewiston, NY)

Kira A, 1966 The Bathroom (Bantam, New York)

Kira A, 1976 The Bathroom new and expanded edition (Bantam, New York)

Kitchin R, Law R, 2001, "The socio-spatial construction of (in)accessible public toilets" Urban Studies 38 287-298

Knight G, Bichard J, 2011 Publicly Accessible Toilets: An Inclusive Design Guide (Helen Hamlyn Centre for Design, London)

Kuran A, 1968 The Mosque in Early Ottoman Architecture (University of Chicago Press, Chicago, IL) Lacey A, 2004 Good Loo Design Guide (RIBA Publishing, London)

Michael Y L, Green M K, Farquhar S A, 2006, "Neighborhood design and active aging" Health and Place $12734-740$ 
Mieczakowski A, Langdon P M, Clarkson J, 2010, “Investigating designers' cognitive representations for inclusive interaction between products and users", in Designing Inclusive Interactions Eds P Langdon, J Clarkson, P Robinson (Springer, London) pp 133-145

Ministry of Administration for Disabled, 2005 2nd Disability Council Commission Report (Nurol Press, Ankara)

Molotch H, Noren L (Eds), 2010 Toilet: Public Restrooms and the Politics of Sharing (New York University Press, New York)

Moore S A, 2002, "Facility hostility? Sex discrimination and women's restrooms in the workplace" Georgia Law Review 36599

Nemeth J, 2009, "Defining a public: the management of privately owned public space" Urban Studies 46 2463-2490

Penner B, 2005, "Researching female public toilets: gendered spaces, disciplinary limits" Journal of International Women's Studies 6 81-98

Penner B, 2009, “(Re)designing the 'unmentionable': female toilets in the twentieth century", in Ladies and Gents: Public Toilets and Gender Eds O Gershenson, B Penner (Temple University Press, Philadelphia, PA) pp 141-151

Preiser W F E, Smith K S, 2010, "Universal design at the urban scale" Universal Design Handbook Eds W F E Preiser, K S Smith (McGraw-Hill, New York) pp 20.1-20.11

Rawls S K, 1988 Restroom Usage in Selected Public Buildings and Facilities: A Comparison of Females and Males PhD thesis, Department of Housing, Virginia Polytechnic Institute and State University, http://trove.nla.gov.au/version/45470757

Serlin D, 2010, "Pissing without pity: disability, gender, and the public toilet", in Toilet: Public Restrooms and the Politics of Sharing Eds H Molotch, L Norén (New York University Press, New York) pp 167-185

Simpson C, 2000, “Judges deny potty parity" Chicago Sun-Times 4 August, page 3

Unsal F, 2009, "International academic association on planning, law and property rights", in Proceedings of the Third Conference Department of Development and Planning, Aalborg University, 11-13 February

Wang H L, Huang S M, 2005, "Equal opportunity restroom code: a knowledge management model" Journal of Architectural and Planning Research 22 1-15

Weisman L K, 1992 Discrimination by Design: A Feminist Critique of the Man-Made Environment (University of Illinois Press, Urbana, IL)

Wright L, 1967 Clean and Decent: The Fascinating History of the Bathroom and the Water Closet and of Sundry Habits, Fashions and Accessories of the Toilet Principally in Great Britain, France, and America (University of Toronto Press, Toronto) 